\title{
Designing a knowledge co-production operating space for urban environmental governance-Lessons from Rotterdam, Netherlands and Berlin, Germany
}

\author{
Niki Frantzeskaki ${ }^{\mathrm{a}, *}$, Nadja Kabisch ${ }^{\mathrm{b}}$ \\ a Dutch Research Institute For Transitions (DRIFT), Faculty of Social Sciences, Erasmus University Rotterdam, The Netherlands \\ ${ }^{\mathrm{b}}$ Humboldt-Universität zu Berlin, Institute of Geography and Helmholtz-Centre for Environmental Research-UFZ, Germany
}

\section{A R T I C L E I N F O}

\section{Article history:}

Received 28 October 2015

Received in revised form 13 January 2016

Accepted 14 January 2016

Available online 27 January 2016

\section{Keywords:}

Knowledge co-production

Governance

Urban ecosystem services

Stakeholder interaction

Sustainability

Urban resilience

Policy

\begin{abstract}
A B S T R A C T
Challenges for a sustainable urban development are increasingly important in cities because urbanization and related land take come up with negative challenges for the environment and for city residents. Searching for successful solutions to environmental problems requires combined efforts of different scientific disciplines and an active dialogue between stakeholders from policy and society. In this paper, we present a comparative assessment of the way policy-science dialogues have achieved knowledge co-production about strategic urban environmental governance action using the cities of Berlin in Germany and Rotterdam in the Netherlands as case studies. The ecosystem services framework is applied as a lens for policy-science interaction and a 'knowledge co-production operating space' is introduced. We show how policy officers, urban planners, practitioners and scientists learned from each other, and highlight the impact of this knowledge co-production for governance practice. We found that the concerted collaboration and co-creation between researchers and policy officers have led to mutual learning and establishment of relationships and trust in both cities. Not only the policy-relevance of research and its policy uptake were achieved but also new insights for research blind spots were created. In our conclusions we reflect on co-production processes with two types of conditions that we introduced to be most influential in the way knowledge can be co-created. These are conditions that relate to the way knowledge co-production processes are set-up and, conditions that relate to the expected value or benefit that the co-produced knowledge will bring across society, policy and practice.

(C) 2016 The Authors. Published by Elsevier Ltd. This is an open access article under the CC BY-NC-ND license (http://creativecommons.org/licenses/by-nc-nd/4.0/).
\end{abstract}

\section{Introduction}

In 2014, more than 54 per cent of the world's population lived in cities (United Nations Department of Economic and Social Affairs, 2014). Seven years after the United Nations announced that now globally, more people live in urban than in rural areas the urban percentage increased even more and will continue to increase. Newest projections suggest that by 2050 around $65 \%$ of the global population will be urban. Next to population increase, global urban land area is expected to grow at a faster rate. Estimations showed that urban land will increase by $1.5 \mathrm{Mio} . \mathrm{km}^{2}$ by 2030 compared to 0.7 Mio. $\mathrm{km}^{2}$ in 2001 (Seto et al., 2011). Urbanization is therefore intrinsically connected to urban land area expansion, which is translated into a need for new housing developments to service more city residents (Haase et al., 2013). Initial processes of

\footnotetext{
* Corresponding author.

E-mail address: n.frantzeskaki@drift.eur.nl (N. Frantzeskaki).
}

urbanization and land take are further connected with negative challenges for the environment and for city residents. Negative challenges include increased levels of noise, air pollution and the decrease of urban green spaces. Challenges for a sustainable urban development will, thus, be increasingly important in cities while the need for robust science to inform strategic environmental policy simultaneously grows (Dilling and Lemos, 2011). However, environmental problems are often difficult to handle and successful solutions require combined efforts of different scientific disciplines but also an active dialogue between stakeholders from policy and society (Lemos and Morehouse, 2005).

Environmental science increasingly recognizes the need to engage with stakeholders from different parts of society in order to not only make knowledge relevant for societal problems but also by realizing the imminent interconnections between human and ecological systems that require new approaches to knowledge production (Jasanoff, 2004; Beunen and Opdam, 2011; Negev and Teschner, 2013). In this context, transdisciplinary approaches for knowledge co-production provide insights about the ways and the 
rationale for engaging with multiple knowledge holders: experts and scientists as well as citizens and practitioners (Bergmann et al., 2012; Jahn et al., 2012). In a positive view, the dialogue between different knowledge holders is beneficial for mutual learning: scientists learn more comprehensively about issues important for policy while stakeholders from society (may) learn by seeing things differently or in new formats.

A policy-science dialogue addressing challenges in cities could help ensure a sustainable urban development and in this way, aid all involved actors to adequately respond to current challenges while reflecting citizen's needs. Cities are currently at cross roads of climate change, urban dynamics and resulting pressures (Elmqvist et al., 2013). At the same time, they need to consider changing demands from citizens about use of public space and retrofitting of private space. In this context the scientific framework of urban ecosystem services was brought into the interface between policy and science to inform urban planning and governance (Frantzeskaki and Tilie, 2014; Kabisch, 2015). Analyses of past and recent policy and planning strategies reveal that there are already different degrees and ways that the ecosystem services framework (ES) and rationale have been integrated in informed urban planning and governance (Hansen et al., 2015; Rall et al., 2015). Urban ecosystem services are described as the benefits urban citizens obtain from the ecosystems in cities (Elmqvist et al., 2013; Millenium Ecosystem Assessment, 2005).

Using the ES framework as a lens for policy-science interaction, in this paper we are focusing on the way policy-science dialogues in a facilitated process have achieved knowledge co-production about strategic urban environmental governance action in two large cities in Europe, Berlin and Rotterdam. In particular, we address the following research questions:

1 Did policy makers and scientists learned from each other through the co-production process?

2 Does the ecosystem service framework enable knowledge coproduction for sustainability and resilience planning?

3 What is the impact of a knowledge co-production for urban environmental governance?

To do so, a comparative assessment is presented using the cities of Berlin in Germany and Rotterdam in the Netherlands as case studies. Both cities deal with challenges of population increases and respective pressure on urban open land for residential purposes. For Berlin, the focus is on the overall green space development of the city, while for Rotterdam the development of the city as a delta city with social-ecologically productive urban ecosystems is particularly important next to green space development planning. In two city contexts we designed and facilitated a policy-science co-production space by building on urban governance context analysis work, transition scenario work and backcasting. In this, we introduced the ES framework to map the multiple benefits of urban ecosystems with the aim to develop a vision and strategic transition pathways at city-scale.

\section{Knowledge co-production in the policy-science interface for urban governance}

\subsection{Identifying the conditions for successful knowledge co-production in the policy-science interface}

Scholarly work on co-production of knowledge has emerged in the last years and elaborates on what makes knowledge usable in an interaction process especially at the policy-science front (Aeberhard and Rist, 2009; Armitage et al., 2011; Beunen and Opdam, 2011; Dilling and Lemos, 2011; for a comparative case study see Healey, 2008; Kemp and Rotmans, 2009; Lemos and
Morehouse, 2005; Pohl, 2008) and on the different good practices surfacing from successful knowledge co-production processes (Jahn et al., 2012; Bergmann et al., 2012; Hirsch Hadorn et al., 2006; Pohl, 2008; Wickson et al., 2006; Polk, 2014; Maasen and Lieven, 2006; Aeberhard and Rist, 2009; Russel et al., 2008; Klein et al., 2001). Co-production refers to the active involvement and engagement of actors in the production of knowledge that takes place in processes either emerging or being facilitated and designed to accomplish such active involvement (Voorberg et al., 2014).

From reviewing the literature we identified two types of conditions that influence the way knowledge can be co-created: (a) conditions that relate to the way knowledge co-production processes are set-up and (b) conditions that relate to the expected value or benefit that the co-produced knowledge will bring across society, policy and practice. The conditions that relate to the way knowledge co-production processes are set up include openness of the process in the form of an open discussion format that enables sharing, inclusivity of actors from multiple disciplines and with different expertise and experiences, and legitimacy of the knowledge contributed to the co-production process. The conditions that relate to the expected value or benefits to be gained from the uptake of the new knowledge include the usability of the co-produced knowledge in dealing with real world problems, and the quick uptake and/or use of this knowledge to a contemporary policy debate or to an issue that is high on the political agenda.

(a) Conditions that relate to the way knowledge co-production processes are set-up

Openly shared knowledge: From transdisciplinary science writings, it is highlighted that bringing together actors from multiple disciplines and with diverse experiences in an open process for sharing and learning is a precondition for co-creating new knowledge for problem solving, altering worldviews and understanding diversity of values and beliefs (Bergmann et al., 2012; Hirsch Hadorn et al., 2007; Polk, 2014). Leith et al. (2014) also point at the importance of connecting different actors to address sustainability challenges especially when these challenges require a learning mode for solution searching. A long-term success story in which scientists and policy officials were engaged in a coproduction process is extensively described in Kemp and Rotmans (2009). The authors highlight the critical success factors that resulted in the inclusion of transition management as a key concept for the ministerial administration in energy innovations in the Netherlands. Among others success factors were the development and use of an open discussion format with a common language, a free and safe environment allowing discussing openly, as well as the willingness for engagement through the whole process (ibid). The design of the engagement process is most effective when it is deliberate and when the needs from both sides are openly discussed and clearly presented right from the beginning. Mutual understanding can be ensured and increased through a repeated interaction process between science and policy (Lemos and Morehouse, 2005).

Inclusive to multiple types of knowledge: The value of integrating different types of expert knowledge is already well argued in interdisciplinary, and transdisciplinary research writings. Empirical work points at the fact that including different types of knowledge (like tacit knowledge and knowledge from experiences) not only produces a more creative output but also ensures the accountability and applicability of the new knowledge for society, policy and practice (Wiek et al., 2004; Polk 2014, Maasen and Lieven, 2006; Aeberhard and Rist, 2009; Miller et al., 2008; Wyborn 2015).

Legitimate knowledge: Cash et al. (2003) summarized that credibility, legitimacy and salience need to be considered as determinants of a successful use of scientific information. 
Particularly credibility is important because it relates to the scientific basis, level of detail in scale and argumentation used. This includes the credibility of technical details, categories and values. Lemos and Morehouse (2005) underline that establishing credibility and trust through the engagement processes makes results more likely to be used in policy development and implementation. Negev and Teschner (2013) point at knowledge co-production to fill the uncertainty gap of technical knowledge. Flexibility is another argument to support knowledge co-production as a mode. Flexibility relates to which research agendas as needs of stakeholders may change during the engagement process but also relates to resources including budgets, timing and duration of projects (Dilling and Lemos, 2011). Time however might be the most constraining factor, as time is often scarce and must be available to handle exercises and finalize work in a satisfactory manner (Lemos and Morehouse, 2005).

(b) Conditions that relate to the expected value or benefit that the co-produced knowledge will bring across society, policy and practice.

Usable knowledge: Lemos and Morehouse (2005) use the example of climate assessments to evaluate what affects the coproduction of knowledge between science and policy. The challenge remains on how to produce and to assess usability of scientifically produced knowledge for policy and what such a process brings for scientists to create high quality scientific outcomes (Beunen and Opdam 2011; Dilling and Lemos, 2011). Usable science in this context may be the one that directly influences decision and policy making (Lemos and Morehouse, 2005). Usability could emerge and be associated with a range of perceptions and capacities. For instance, time is such an issue as scientific knowledge might be perceived usable after some time has passed (ibid) and the learning process may take a long time as e.g., in the case of adaptive learning in Canada's Arctic (Armitage et al., 2011). In other cases, such as in the case of co-production of knowledge in organic agriculture, research and implementation happened side by side and in constant interaction lessening the temporality gap and ensuring usability (Aeberhard and Rist, 2009). In the view of building knowledge on climate change adaptation, Dilling and Lemos (2011) highlighted the importance of iterativity. They describe iterativity as "the purposeful and strategic interaction between climate knowledge producers and users so as to increase knowledge usability ..." (p. 681). Accordingly, knowledge co-production processes that tune in creating solutionoriented knowledge are preconditioned to succeed since they gain commitment and focus from the start (Gibbons, 1999; Lang et al., 2012).

Actionable knowledge: Knowledge generated has to be applicable and relevant for policy action or as Vilsmaier and Daniel (2015) argue knowledge generated has to be actionable knowledge. Policy officers and scientists could benefit from a continuous interaction as this builds diverse knowledge networks and allows sharing and capitalizing of knowledge from different actors (Albert et al., 2014). Through networks (formal or informal), working partnerships and relationships, information is shared and new knowledge is built fostering inclusion of new communities (Armitage et al., 2011; Dilling and Lemos, 2011). As an important outcome of the knowledge co-production for scientists, Kemp and Rotmans (2009) describe an improved link to the ministerial agenda, improved networks with business but also the development of the research networks as indispensable to co-produce and continuously advance the produced knowledge.

\section{A knowledge co-production process in two European cities}

\subsection{Case study cities}

\subsubsection{Berlin}

As the largest city of the Germany, Berlin is today home to more than 3.5 million inhabitants. Berlin is situated in the eastern part of Germany and its administrative boundaries extend over a region of more than 89,000 ha. Population increase in the last decade has coincided with an increase in the size of residential areas by $18 \%$ while urban green spaces including public green spaces and forest areas increased at a lower extent by only $3 \%$. Nevertheless, the city contains public green spaces and forest areas which represent more than $30 \%$ of the city area. They include parks of more than 10 ha, private yards, allotments, cemeteries, recreational areas, sport grounds and street green. The largest urban green space in Berlin is Tempelhof, the former city airport. This is one example where changing land use has created a large green space in the city with an area of more than 300 ha.

Population projections predict an increase of 254,000 additional inhabitants by 2030 , which will particularly raise the demand for housing in the next years (around 137,000 new flats are planned by 2030). Thus, Berlin faces significant uncertainties concerning land use change, particularly due to the predicted residential development but also due to climate change. Processes related to climate change have resulted in more frequent summer heat waves, droughts and higher air temperatures in the city in the last years. Berlin has responded to these challenges by introducing and implementing plans and strategies to protect and develop urban green spaces. As an addition to the landscape plan, these strategies include the Urban Development Plan for Climate, Berlin's Landscape Strategy and a Biodiversity Strategy. These administrative planning strategies and policies are complemented by a number of local, bottom-up initiatives to green and sustain the urban environment, such as community gardening, education projects and guerilla gardening movements.

\subsubsection{Rotterdam}

The Dutch city of Rotterdam is situated in the Rhine-Meuse Delta on the North Sea. The city is a thriving metropolis with over 610,000 inhabitants and 173 represented nationalities. Rotterdam is the largest port in Europe and an international center for trade and distribution acting as the main gateway to Europe for many emerging economies in Asia, the Middle East and South America. In addition to being a major port and commercial hub, Rotterdam has 117 public parks ( 1765 ha in total), $500,000 \mathrm{~m}^{2}$ green roofs and 747,000 trees, making it one of greenest cities in the Netherlands. Green space covers $19.7 \%$ of the total city surface, while $34.9 \%$ of the city is composed of water (Gemeente Rotterdam, 2011). However, as the lowest-lying delta in Europe (90\% of the city is below sea level $^{1}$ ), Rotterdam faces significant environmental uncertainties and pressures.

The city has dealt with these challenges extensively in the last years through very adaptive planning and good implementation processes of plans and pilots as well as through a number of innovative initiatives, which aim to ensure effective climate governance and green spaces maintenance and extension. This includes a series of pilot projects, which demonstrated how to better integrate green with protective infrastructure measures in order to protect against flooding and mitigate climate change. There are also a number of successful citizen initiatives promoting urban farming and agriculture, which bring people closer to the

\footnotetext{
${ }^{1}$ http://www.iclei-europe.org/members/member-in-the-spotlight/archive/rotterdam/
} 
food production process.

\subsection{Why it is relevant to have a co-production process in these two} cities

Urban environmental problems are not longer puzzles for experts to solve but have become issues of public debate in which knowledge from multiple actors is needed for effective interventions and inclusive governance approaches to be put in place. Specifically, Berlin and Rotterdam are challenged by residential demands and competition for land. Climate change further challenges both cities with Rotterdam being affected by predicted flooding events and Berlin being affected by increased temperatures. Both cities face the impacts of budget cuts and seek new ways to ensure the maintenance of good quality of urban services for citizens while continuing to innovate in adaptation plans for climate change.

Both cities have a legacy of good planning and an open interaction with scientists and businesses. Planners and policy officers are well versed to co-create narratives for visions of the city, and to accommodate new knowledge inputs to their on-going plans. As thus, they are open and capable to engage in a coproduction process for new and/or persisting challenges.

In both cities, the new common challenge is how to connect plans and actions realized on the short term (within a 3-5 year time horizon) with long-term visions on greening the city and improving environmental quality of the city in the face of the contextual pressures (urbanization and climate change pressures). Scientific knowledge is requested to explain and examine the benefits in terms of ecosystem benefits that green-blue infrastructures provide currently, so as to create an evidence-base for the positive effect of exiting green plans and measures and in this way support future decisions. Connecting scientific knowledge to local context and becoming relevant for local dynamics and problems is a process of translation and co-creation. As such, setting up a knowledge co-production operating space for the cities aimed at creating capacity for sustainability and resilience learning in a dialectic way (Vilsmaier and Daniel, 2015).

\subsection{Setting up a knowledge co-production operating space}

Studies on stakeholder engagement and interactive research use different models of engagement and interactive research within the context of environmental problems (Lemos and Morehouse, 2005). In this paper we designed and applied a 'knowledge co-production operating space' in two cities (Leith et al., 2014; Pereira et al., 2015). We build from the conditions identified as essential for successful knowledge co-production in the policy-science interface in Section 2. The proposed coproduction operating space was used to inform both scientists working in a collaborative European research (http://cbc.iclei.org/ about-urbes) and urban environmental planners and practitioners in the cities of Berlin and Rotterdam.

The process includes three phases: (a) a preparatory phase (b) a discovery phase and (c) the knowledge consolidating phase.

The preparatory phase has the objective to identify the problem at the policy-science interface that requires a new knowledge coproduction process for its solution orientation. Open dialogue in a setting of a workshop or a small-group forum is facilitated with the objective to identify the multiple layers and variables of the problem as well as its spatial manifestations. In this way, the knowledge co-production is tailored and tuned to directly contribute to a real life problem (ensuring the usability and quick uptake of new knowledge).
The discovery phase includes three steps: (i) social-ecological context identification, (ii) unmasking gaps and mismatches between planning practices and social demands and (iii) scenario development that connect discovering problems and untapped potentials in the city (the contextual knowledge - Wyborn (2015) with future pathways of co-creation (the desirable or normative knowledge - Wyborn (2015). It is important to first examine the contemporary dynamics and the existing knowledge capital across different actors and subjects in order to identify the socialecological context. For doing so, scientific knowledge relevant for the urban issue in each city was identified and/or generated and brought forward in the form of urban environmental quality assessments, indicator schemes from the cities and other social analyses of interests and preferences of citizens about urban ecosystems and urban quality. Local, insider and tacit knowledge on the planning and governance processes has been gathered by engaging with policy officers and planners from different departments and with different roles within the local administration (strategic, tactical, operational or monitoring). In this discovery step inclusivity of different knowledge holders and legitimacy of knowledge inputs are (recommended to be) ensured.

The second step includes the identification of mismatches between urban planning and policy practice and social demands that is realized by contrasting the areas (places) and issues that enjoy policy attention and the areas (places) and issues that social demand for solutions are identified. In this step sharing insight knowledge on place dynamics, place identity characteristics and experiences from engaging with community enriches both knowledge of experts (scientists) and practitioners (policy officers, consultants) and community representatives.

The third step is about forward looking in creating a shared vision and strategic pathways for action and solution orientation. For vision creation, we used the method of perspectives and scenario workshop where participants guided by the ES framework provided their desirable state for a perspective of 15 years ahead in Berlin and 50 years ahead for Rotterdam. From the desired vision, backcasting was used to generate actions and to identify conditions to achieve the desirable vision. For doing so, we combined qualitative inputs from the previous two steps with quantitative baseline ES assessments in the cities in the form of maps and indicator change values.

The third phase - the knowledge consolidating phase - is about developing the outputs with the aim to disseminate them in various target audiences and utilize the knowledge co-produced for policy development and implementation. We developed the outputs in different formats: scientific presentations and publications, videos and policy briefs for policy officers and planners as well as on simple presentations or social media formats for broader dissemination to practitioners, NGOs and civil society groups.

\section{Renewing urban environmental governance via a knowledge co-production operating space}

\subsection{The Berlin knowledge co-production}

The policy-science knowledge co-production in Berlin revealed several issues. In the discovery phase it became clear through a number of in-depth interviews that Berlin's planning institutions have already developed a certain knowledge and expertise on the benefits of different urban green spaces. Although members of planning institutions do not use the term "ecosystem service" they are aware of the benefits created by urban ecosystems. This was achieved by the development of the different planning strategies such as, the development of new green spaces, and the transformation of former brownfield sites into public urban green spaces and the maintenance of existing ones. 
It was highlighted that a number of collaboration projects already exist. These collaboration projects include citizen-driven local initiatives and the city administration. They focus on ecosystem services of food production, educational learning and fostering social coherence. Examples of those collaboration projects are backyard and community gardening such as the Prinzessinnengärten that are valuable for social learning (Bendt et al., 2013), guerilla gardening around tree discs in Friedrichshain, subsistence farming and urban agriculture (www.stadtacker.net), and environmental education projects in school gardens or, at the Tempelhofer Feld. There exist informal initiatives such as the 'Mundraub Berlin', a web-based information platform on urban foraging (www.gratis-in-berlin.org). All these projects allowed for creativity and supported tolerance by bringing together people of different ethnic and socio-economic backgrounds, age groups and interests. They have a positive influence on sustainable economic development, health and social cohesion and ease interaction between different communities Photo 1 .

Challenges remain in the overall governance and planning of urban spaces. The identification of the context situation and more detailed, the scenario work identified challenges related to future population growth and climate change. Stakeholders discussed the need to develop more housing areas while maintaining green spaces - also including allotment gardens - for recreational use and for counteracting climate change over the coming decades. An urban growth scenario was developed that addresses the needs to accommodate new citizens while simultaneously responding to foreseen climate change.

The presentation of a final scenario map during the workshop session which was developed jointly stimulated a vivid discussion among stakeholders on the potential residential development areas in Berlin and on ways to overcome obstacles to implementing these. Urban densification was mostly considered plausible for areas hosting one-family houses and villas in the outer parts of the city. Based on these assumptions and expected land-use changes, the provision of ecosystem service was calculated and visualized using a Geographical Information System (GIS). As an example, pollution control, an important ecosystem service, was used as a starting point of discussion.

Ecosystem services provisioning was implemented in the future scenario by the densification of single house and villa areas and by greening of roofs. As a result, densification will lead to a decrease in recreational areas. Green roofs will increase the potential of absorbing particles and reducing air pollution. Particularly the land-use scenario maps and the related change values of ES (such as per capita green space or potential carbon sequestration) have been assessed by the stakeholders to be very helpful 1) in

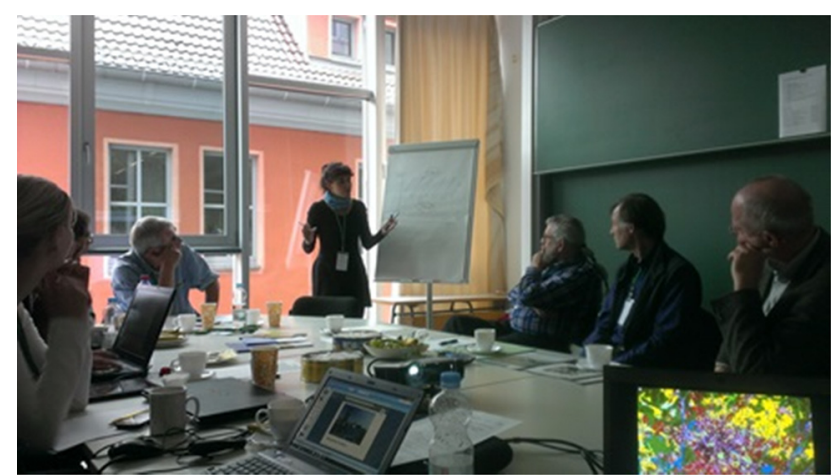

Photo 1. Inside the Berlin workshop on scenario development for urban ecosystem management and governance. (Photo credits: Nadja Kabisch). structuring the knowledge provision and 2) stimulating the dialogue and discussion in order to identify their specific area of work, both in terms of topical and spatial work and 3) to be used as arguments in favor for further green space development and maintenance in future budget deliberations.

\subsection{The Rotterdam knowledge co-production}

In the discovery phase in Rotterdam, it was revealed that Rotterdam's planning institutions have capacity and knowledge to integrate new knowledge, and to dialectically identify how new assessments and innovations for urban spaces can fit in the existing plans and strategies. The planning tradition and practice in the city is rather well structured and standardised with a sustainability focus. Planners were unfamiliar with the term ES, and the introduction of the ES framework allowed for a critical assessment of existing pilot places for enhancing climate resilience such as greening of the waterfronts, the water square, the green rooftops and the creation of urban gardening places in schoolyards.

In the discovery phase, participants identified gaps and mismatches in terms of how blue and green infrastructures even though integrated in the urban vision that pre-exists, in planning practice they remain disconnected and that may result in a compromising of ecosystem services provisioning. At the same time, another missed opportunity that participants identified was that pilots with potential multi-functionality and high degree of ES supply are not adequately evaluated and this results in limited capitalization of their benefits and lessons (Frantzeskaki and Tilie, 2014) Photo 2.

With view of these mismatches and gaps, as well as with identified opportunities to achieve higher levels of urban resilience and sustainability through ES, the participants co-created a very inspiring vision to guide future action for Rotterdam's transition to urban resilience that encompasses all the ES and views the city as an edible city with healthy and productive water ecosystems that people enjoy, a healthy city with good quality green spaces that are maintained and celebrated, circular city that stewards green and blue infrastructure (Rotterdam Policy Brief \#1, 2014 the URBES Project).

During the development of strategic pathways for achieving the identifying vision and bridging the identifying gaps of practice, participants identified co-benefits between policy programs that had not been further explored such as the way climate adaptation policy recognizes the waterfront restoration projects only for water

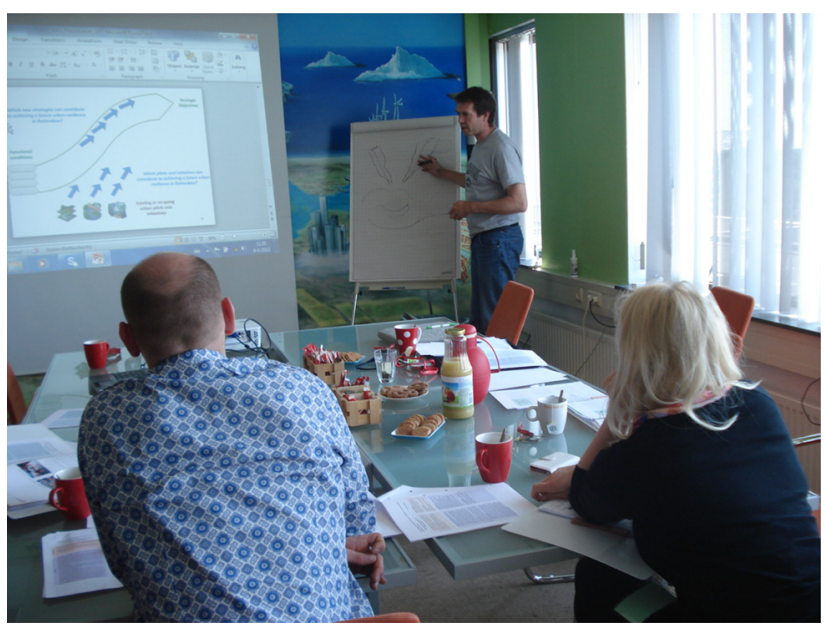

Photo 2. Inside the Rotterdam workshop on scenario development for urban ecosystem management and governance-Image of one of the break-out groups discussing future scenario developments. (Photo credits: Niki Frantzeskaki). 
retention and how they can further be linked with green wedges and corridors development to provide recreational and amenity functions.

During the sharing and capitalizing phase, in both cities, researchers engaged with policy officers, urban and regional planners and pioneers from civil society initiatives to disseminate the new narratives of 'understanding' urban ecosystems and the challenges of their governance in the form of two videos (http:// www.cbc.iclei.org/URBES-videos). The respective scripts were a product of co-creation including open and unstructured interviews with the involved stakeholders of the city of Berlin and the city of Rotterdam. The videos were produced by a group of media and communication graduates with the aspiration to become documentary producers guided by the communication officer of the URBES Project and the authors. The produced videos served not only for sharing and disseminating results and ideas across different departments of the two cities but also as an inspiration and sharing source across different cities. In 2014 the Rotterdam video was nominated as one of the most influential videos for climate change and got awarded by the World Bank's program Action4Climate and earthwatch.com and was broadcasted in New York's Times square during Earth's day. In the same year, authors were invited to present the Berlin video at the Environmental Education Conference in the Berlin mayor's hall and at the European conference for renaturing cities in Milan, Italy organized under the auspices of the Italian Presidency of the European Union.

\section{Discussion and conclusions}

\subsection{Co-production of knowledge: which knowledges and what for?}

\subsubsection{Policy Learning}

In co-productive processes, policy learning is a direct and indirect outcome of the process that relate to building governance capacity for adaptation to context dynamics and opportunities (Wyborn, 2015). In Rotterdam the main policy learning outcome that was achieved in the process is the ability to reflect on the way evaluation of pilots and community initiatives is realized in order to be as evidence grounds for adapting planning strategies and plans in the future as well as for deciding on resource appropriation for scaling effective pilots and plans. Which pilots will be earmarked as cases to be replicated in the future? Which initiatives will be highlighted for adapting plans for use of vacant or public space? Policy officers were able to adopt messages from the coproduction process to their daily work e.g., the reflection on how to monitor pilots was brought up to the policy agenda setting of the city by the participants as an expressed policy need. Learning on how to view current policy developments and their impacts as well as societal developments from an integrated perspective like the ES framework helped in reflecting on what works and what is still lacking in urban planning. The transition pathway on bio-cultural economy for Rotterdam was also further developed as a strategy in the 'Urban By Nature' vision document the city of Rotterdam developed for the International Architectural Biennale in 2014.

In Berlin, policy learning was mainly achieved through the engagement process in the scenario work in the land use change maps and the resulting change values of different ES. A critical reflection of the current land use situation and possible changes through future population increase in Berlin as well as the related different ES values emerged and raised new views on how to deal with the challenge of population growth. The scenario maps were found useful for communication and awareness rising and for initiating a discussion. Through the process new ideas were brought up and were thought to be implemented into current land use planning. In terms of what was brought up to a next phase, participants expressed the need to use the ES framework and the knowledge gained through the scenario work to ensure that ongoing green space projects continue receiving funds for their implementation. It was highlighted that the discussed issues during the process should be used to increase legitimacy and justification of providing nature in cities.

\subsubsection{Scientific learning}

From the perspective of a knowledge co-production operating space, we found that not only policy officers and planners benefited with new knowledge, but also scientists discover new aspects and learnt throughout the dialogues.

In Rotterdam, researchers involved in the process realized the different forms of knowledge that are needed in policy and planning practice, including context specific knowledge but also city-wide assessment knowledge. Specifically, scientists learnt how to put knowledge on ES from regional assessments into images and examples for locally specific elements especially in waterfront areas and in explicating potential solutions in the built environment. During the co-production phase, the planners identified selection criteria on existing pilots on urban renaturing that are to be considered for scaling-up and scaling-out (replicating) that until then remained an opaque topic; a topic with limited knowledge. Additionally, scientists learned that scientific frameworks and concepts such as "resilience" or "ecosystem services" need to be explained in detail right from the beginning of the engagement process and to connect with existing cases or examples so as to become relative to frameworks and concepts used in everyday planning practice. Last, from the co-production phase, scientists involved in the process learnt how important it is to show the added knowledge and practice value of new frameworks and concepts.

In Berlin, knowledge by scientists was created through the process of discussing several issues as drivers for the most pressing challenges the city faces today. During the co-production phase, the identification of population increase as the main driving force of future urban land use change was identified. Scientists learned how priorities are set in urban planning and policy-making institutions in the city, which included the prioritization of potential land use areas for a certain purpose. Nature in cities as the precondition for ES provision was highlighted as important but probably not at the first place when decisions are done, which city department finally gets the money to implement projects. Knowledge from planners and policy makers was transferred to scientists who could use it for scenario building, which made them then sound more realistic and understandable. It became also clear, that simple projections are more interesting for stakeholders for communication to the broad public while details are more relevant in the implementation process. In terms of methodological application, scientists learned from the process that scientific terms such as "scenario building" or "ecosystem service framework" need to be explained in detail right from the beginning of the engagement process to reduce complexity in terminology use.

In our processes, we involved policy officers across different city departments to ensure that multiple ecosystem services are recognized and accounted for during the co-production process. We are aware that fragmentation and lack of communication between the city departments could be a persisting barrier for knowledge sharing and advancement in cities, and as such may hurdle integration of new frameworks in policy practice (Frantzeskaki and Tilie, 2014). It is therefore the responsibility of the organizers of knowledge co-production processes during the preparation phase (Table 1 ) to carefully select which stakeholders across city departments will participate to lessen this fragmentation problem. At the same time, we recognize that involving representatives from civil society like NGOs and community 
organisations in the process ensured the inclusion of community's knowledge and experience. The missing actor in our process is the local or international businesses (small-medium or even large scale ones). This was a choice decided during the preparation phase due to the expressed policy need to strengthen relations and interactions with communities for urban ecosystem's planning and due to the highly strategic-learning orientation of the overall process within the cities. We however suggest that organizers of knowledge co-production operating spaces in cities can consider the participation of business actors that relate to implementation of greening projects and nature-based solutions. The process we outlined in this paper does not exclude or preclude specific actors but rather proposes that a variety of knowledge holders is essential for a successful knowledge co-production.

Overall, in both case study contexts, the concerted collaboration and co-creation between researchers and policy officers lead to mutual learning and establishment of relationships and trust. We found that not only policy-relevance of research and its policy uptake occurred but that also new insights for research blind spots were created.

\subsection{Ecosystem services as an enabling or disabling frame for understanding urban ecosystems and their governance}

During the co-production process, it became clear that the ES framework proved to be a useful assessment framework to show how urban ecosystems provide certain benefits to city residents. In this sense, it enabled the understanding of ecosystem services by being used as a mapping tool and communication tool to the multiple ES. As such, ES were narrative 'devices' that bridged the different languages and meanings of researchers and stakeholders in a dialogue about where and in which way they are produced and where the impoverished areas are in cities that require policy attention.

Even when planners recognized the value of the ES framework, or, expressed a need for a more integrative framework, a translation process is needed to deal with the terminological complexity and this translation process needs also to be tailored for or 'adapted' from the local planning practice. Arguably the most salient characteristic of the ES framework is the integrated perspective it brings and the complexity that comes with it. At an organizational level, the ES framework can be also employed to map possible collaborations and connections between different city departments and the resulting possible designed solutions to aim at ES mixes. Additionally, it is important to consider existing knowledge of planners, policy officers and other stakeholders when introducing the ES framework and the ways in which ES are added onto existing planning tools. Future research needs to put effort on evaluating how the framework is and can be applied with an explicit focus on its analytical strength for urban environmental governance.

\subsection{Impact of knowledge co-production in urban environmental governance}

Knowledge production and knowledge capitalization are processes that create value and governance capacity since knowledge is a strategic asset hence focusing on co-creating knowledge benefits society, policy and practice. Using the lens of $\mathrm{ES}$, in this paper we showed a way policy-science dialogues in a facilitated process have achieved knowledge co-production about strategic urban environmental governance action in the cities of Berlin and Rotterdam. According to the introduced conditions that influence the way knowledge can be co-created - conditions that

Table 1

Overview of the phases of knowledge-co-production operating space and how it was implemented in each case study.

\begin{tabular}{|c|c|c|c|}
\hline Phases & Rotterdam & Berlin & $\begin{array}{l}\text { Knowledge } \\
\text { Co-production Conditions }\end{array}$ \\
\hline Preparation & $\begin{array}{l}\text { Scoping and setting the context to develop an understand } \\
\text { addressed (discussion and document analysis) } \\
\text { Identifying relevant key participants in co-production proc } \\
\text { draw out the influence in relation to urban green space } \\
\text { In Rotterdam, the participants included policy officers } \\
\text { from the urban planning department, sustainability } \\
\text { department, and the ecology office, green NGOs' } \\
\text { representatives and environmental science researchers } \\
\text { that were invited to an open dialogue workshop }\end{array}$ & $\begin{array}{l}\text { ing of the system and its actors in relation to the problem } \\
\text { cess through document analysis, researcher focus group to } \\
\text { planning } \\
\text { In Berlin, the participants included urban planners from } \\
\text { public administrations (Senate Department of Urban } \\
\text { Development and the Environment; District Department } \\
\text { for Urban Green Development, a park management } \\
\text { group), a public enterprise (stated owned service } \\
\text { company for green spaces), and a green NGO }\end{array}$ & $\begin{array}{l}\text { Openness } \\
\quad \& \\
\text { Inclusivity determined by } \\
\text { content and process objectives }\end{array}$ \\
\hline \multicolumn{4}{|c|}{ 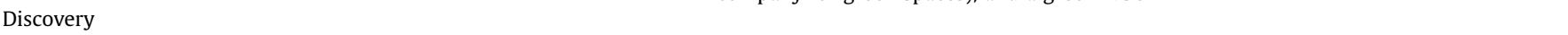 } \\
\hline $\begin{array}{l}\text { Social- } \\
\text { ecological } \\
\text { context } \\
\text { identification }\end{array}$ & $\begin{array}{l}\text { In-depth interviews (identification of major needs and } \\
\text { challenges in urban green and blue infrastructure } \\
\text { planning and where the policy attention for ES lies) with } \\
58 \text { policy officers across different sectoral departments of } \\
\text { the city. City officers had a policy experience of 5-10 } \\
\text { years \{Note } 1 \text { \} }\end{array}$ & $\begin{array}{l}\text { In-depth interviews (identification of major needs and } \\
\text { challenges in urban green space planning and ESS) with } \\
8 \text { key informants from administrative planning } \\
\text { institutions }\end{array}$ & Legitimacy of knowledge inputs \\
\hline $\begin{array}{l}\text { Unmasking } \\
\text { gaps and } \\
\text { mismatches }\end{array}$ & $\begin{array}{l}\text { A 4-h long workshop with } 17 \text { stakeholders (urban } \\
\text { planners, green NGOs' representatives and } \\
\text { environmental science researchers) that included: } \\
\text { presentation of findings from interviews and land-use } \\
\text { mapping with ES (April 2013) }\end{array}$ & $\begin{array}{l}\text { A first workshop with } 6 \text { stakeholders (urban and regional } \\
\text { planners, NGOs' representative and environmental } \\
\text { science researchers) that included: presentation of } \\
\text { methodological approach for land use options, } \\
\text { identification of main driver of land use change, } \\
\text { discussion of rules (September 2013) }\end{array}$ & $\begin{array}{l}\text { Usability of knowledge by } \\
\text { directly pointing at gaps and } \\
\text { mismatches of knowledge and } \\
\text { practice }\end{array}$ \\
\hline $\begin{array}{l}\text { Scenario } \\
\text { development }\end{array}$ & $\begin{array}{l}\text { Two workshops and } 1 \text { focus group with } 17 \text { stakeholders } \\
\text { focused on the development of a urban scenario on urban } \\
\text { resilience, discussion on ways to increase ES provision in } \\
\text { the city and scaling of pilots that produce multiple ES } \\
\text { (May, June and September 2013) }\end{array}$ & $\begin{array}{l}\text { A second workshop with } 4 \text { stakeholders including the } \\
\text { presentation of urban growth scenario, discussion of } \\
\text { impacts on ecosystem service provision (April, 2014) }\end{array}$ & $\begin{array}{l}\text { Usability of knowledge by } \\
\text { linking to objectives and future } \\
\text { aspirations }\end{array}$ \\
\hline $\begin{array}{l}\text { Sharing and } \\
\text { capitalising }\end{array}$ & \multicolumn{2}{|c|}{$\begin{array}{l}\text { Output development through consolidation and dissemination (factsheets, policy brief, scientific publications, } \\
\text { training sessions) (September 2013-September 2014) }\end{array}$} & $\begin{array}{l}\text { Actionable Knowledge: } \\
\text { Quick uptake by disseminating/ } \\
\text { sharing with multiple } \\
\text { beneficiaries }\end{array}$ \\
\hline
\end{tabular}

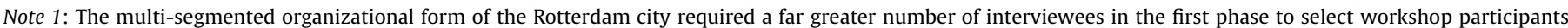


relate to the way knowledge co-production processes are set-up and conditions that relate to the expected value or benefit that knowledge will bring across society, policy and practice - the following conclusions can be drawn.

In Berlin, openness of the process was reached through the open discussion format during the workshops that enabled sharing, inclusivity of all participants from the different disciplines including planning administrations, NGOs and science which all had different expertise and experiences. Legitimacy of the knowledge was reached through the transparent sharing of information which also included information about scale, data used and general background or tacit knowledge. Usability of the coproduced knowledge relates to an uptake and/or use of knowledge to a policy debate of an issue that is high on the political agenda. The knowledge created during the presented process may enter the policy agenda as participants from administration underlined that they now better understand what residential development might mean in the future and which argumentation they could use (from the process) for future budget negotiations.

In Rotterdam, the co-produced knowledge was directly actionable and usable. In the discovery phase, participants reflected upon the way the ES framework was applied and how it can be further used in their planning practice as an analytic or heuristic device. They concluded that the concept of ES is a supporting concept for planning and policy making to advocate the importance of ecosystems' protection as well as the multiple benefits gained from restoring and maintaining existing urban ecosystems. The ES framework was seen as a useful strategic tool to structure discussions and thinking about multifunctional spaces and assessment of existing pilots for climate resilience that can supplement but not replace existing planning frameworks. As such, the ES framework was understood as a tool to move forward from climate focused discussions and address social and economic benefits in an integrated way. The policy officers not only openly shared and provided legitimate knowledge in the process, but also learnt to apply the ES in their practice and thinking as well as used the produced knowledge on mismatches, visions, actions and conditions in related work for urban sustainability.

Reflecting on the co-production process in both Berlin and Rotterdam, we are aware that both cities are very frequently on the light-spot of research institutes and European research projects given the openness to collaborate in such fora as well as the cultivated trust relations and ties of planners to researchers. Recognizing that this creates additional and continuous servicing of both science and policy actors, we urge for creating capacity and ties to cities that are currently on the hinterlands of scientific interest.

\section{Acknowledgements}

This research was funded by the ERA-Net BiodivERsA, with the Dutch National Funder NWO and the German Federal Ministry of Education and Research, both part of the 2011 BiodivERsA call for research proposals and was conducted within the BiodivERsA research project URBES (2011-2014). We would like to thank the interviewees for their time, the participants of the URBES project workshop series for their time and commitment and the researchers of URBES project for internal review comments during the set-up of this research. Last but not least, we would like to thank Prof. Thomas Elmqvist for his continuous support on tryingout new approaches and new methods within the URBES project.

\section{References}

Aeberhard, Andrea, Rist, Stephen, 2009. Transdisciplinary co-production of knowledge in the development of organic agriculture in Switzerland. Ecol. Econ. 1181. doi:http://dx.doi.org/10.1016/j.ecolecon.2008.08.008.
Albert, Christian, Hauck, Jennifer, Buhr, Nina, von Haaren, Christina, 2014. What ecosystem services information do users want? Investigating interests and requirements among landscape and regional planners in Germany. Landsc. Ecol. 2011 (January (31)) doi:http://dx.doi.org/10.1007/s10980-014-9990-5.

Armitage, Derek, Berkes, Fikret, Dale, Aaron, Kocho-Schellenberg, Erik, Patton, Eva, 2011. Co-management and the co-production of knowledge: learning to adapt in Canada's Arctic. Global Environ. Change 21 (3), 995-1004. doi:http://dx.doi. org/10.1016/j.gloenvcha.2011.04.006.

Bendt, Pim, Barthel, Stephen, Colding, Johan, 2013. Civic greening and environmental learning in public-access community gardens in Berlin. Landsc. Urban Plann. 109 (January (1)), 18-30. doi:http://dx.doi.org/10.1016/j. landurbplan.2012.10.003.

Beunen, Raoul, Opdam, Paul, 2011. When landscape planning becomes landscape governance, what happens to the science? Landsc. Urban Plann. 100 (April (4)).

Bergmann, M., Jahn, T., Knobloch, T., Krohn, W., Pohl, C., Schramm, E. 2012. Methods for Transdisciplinary Research. Campus Reader, pp. 1-294.

Cash, David William, Clark, William C., Alcock, Frank, Dickson, Nancy M., Eckley, Noelle, Guston, David H., Ja, Jill, Mitchell, Ronald B., 2003. Knowledge systems for sustainable development. PNAS 100 (14), 8086-8091. doi:http://dx.doi.org/ 10.1073/pnas.1231332100.

Dilling, Lisa, Lemos, Maria Carmen, 2011. Creating usable science: opportunities and constraints for climate knowledge use and their implications for science policy. Global Environ. Change 21 (2), 680-689. doi:http://dx.doi.org/10.1016/j. gloenvcha.2010.11.006

Elmqvist, T., Fragkias, M., Goodness, J., Güneralp, B., Marcotullio, PJ., McDonald, R.I., Parnell, S., et al., 2013. Global Urbanisation, Biodiversity and Ecosystem Services: Challenges and Opportunities. Springer.

Frantzeskaki, Niki, Tilie, Nico, 2014. The dynamics of urban ecosystem governance in Rotterdam, the Netherlands. Ambio 43 (May (4)), 542-555 doi:10.1007 s13280-014-0512-0 http://www.pubmedcentral.nih.gov/articlerender.fcgi? artid=3989510\&tool=pmcentrez\&rendertype=abstract.

Gemeente, Rotterdam, 2011. Rotterdam for European Green Capital 2014.

Haase, Dagmar, Kabisch, Nadja, Haase, Annegret, 2013. Endless urban growth? On the mismatch of population, household and urban land area growth and its effects on the urban debate. PloS One 8 (January (6)), e66531 doi:10.1371/ journal.pone.0066531 http://www.pubmedcentral.nih.gov/articlerender.fcgi? artid=3688765\&tool=pmcentrez\&rendertype=abstract.

Hansen, Rieke, Frantzeskaki, Niki, Mcphearson, Timon, Rall, Emily, Kabisch, Nadja, Kaczorowska, Anna, Kain, Jaan-henrik, Artmann, Martina, Pauleit, Stephan, 2015. The uptake of the ecosystem services concept in planning discourses of European and American cities. Ecosyst. Serv. doi:http://dx.doi.org/10.1016/j. ecoser.2014.11.013.

Healey, Patsy, 2008. Knowledge flows, spatial strategy making, and the roles of academics. Environ. Plann. C 26 (5), 861-881 doi:10.1068/c0668 http://www. envplan.com/abstract.cgi?id=c066).

Jahn, T., Bergmann, M., Keil, F., 2012. Transdisciplinarity: between mainstreaming and marginalization. Ecol. Econ. 79, 1-10.

Jasanoff, S., 2004. The idiom of co-production. In: Jasanoff, S. (Ed.), States of Knowlege: The Co-Production of Science and Social Order. Routledge, New York, pp. 1-12.

Kabisch, Nadja, 2015. Land use policy ecosystem service implementation and governance challenges in urban green space planning-the case of Berlin, Germany. Land Use Policy 42, 557-567. doi:http://dx.doi.org/10.1016/j. landusepol.2014.09.005.

Kemp, René, Rotmans, Jan, 2009. Transitioning policy: co-production of a new strategic framework for energy innovation policy in the Netherlands. Policy Sci. 42, 303-322. doi:http://dx.doi.org/10.1007/s11077-009-9105-3.

Leith, P., O’Toole, K., Haward, M., Coffey, B., Rees, C., Ogier, E., 2014. Analysis of operating environments: a diagnostic model for linking science, society and policy for sustainability. Environ. Sci. Policy 39, 163-171. doi:http://dx.doi.org/ 10.1016/j.envsci.2014.01.001.

Lemos, Maria Carman, Morehouse, Barbara J., 2005. 'The co-production of science and policy in integrated climate assessments'. Global Environ. Change 15, 57-68. doi:http://dx.doi.org/10.1016/j.gloenvcha.2004.09.004.

Millenium Ecosystem Assessment, 2005. Ecosystems and Human Well-Being: Synthesis.

Negev, Maya, Teschner, Naama, 2013. Rethinking the relationship between technical and local knowledge: toward a multi-type approach. Environ. Sci. Policy 30 (June), 50-59 doi:10.1016/j.envsci.2012.10.011 http://linkinghub.elsevier.com retrieve/pii/S1462901112001827.

Polk, M., 2014. Transdisciplinary co-production: designing and testing a transdisciplinary research framework for societal problem solving. Futures 65 , $110-122$.

Pohl, Christian, 2008. From science to policy through transdisciplinary research. Environ. Sci. Policy 11 (February (1)), 46-53 doi:10.1016/j.envsci.2007.06.001 http://linkinghub.elsevier.com/retrieve/pii/S1462901107000731.

Rall, Emily, Kabisch, Nadja, Hansen, Rieke, 2015. A comparative exploration of uptake and potential application of ecosystem services in urban planning. Ecosyst. Serv. 16, 230-242. doi:http://dx.doi.org/10.1016/j.ecoser.2015.10.005.

Rotterdam Policy Brief \#1, 2014. Rotterdam Policy Brief \#1, 2014, the Urbes Project (http://cbc.iclei.org/Content/Docs/01-URBES-pb\%20Rotterdam\%2026\%20Jan. pdf).

Seto, Karen C., Fragkias, Michail, Güneralp, Burak, Reilly, Michael K., 2011. 'A metaanalysis of global urban land expansion'. PLoS One 6 (8), 1-9 (10.1371/Citation). 
United Nations Department of Economic and Social Affairs, 2014. Population Division. 2014. World Urbanization Prospects: The 2014 Revision, Highlights (ST/ESA/SER.A/352)

Vilsmaier, Uli, Daniel, Lang J., 2015. Making a difference by marking the difference: constituting in-between spaces for sustaianbility learning. Curr. Opin. Environ. Sustainability $16,51-55$.

Voorberg, W.H., Bekkers, V.J.J.M., Tummers, L.G., 2014. A systematic review of cocreation and co-production: embarking on the social innovation journey. Public Manage. Rev. doi:http://dx.doi.org/10.1080/14719037.2014.930505.

Wyborn, C., 2015. Co-productive governance: a relational framework for adaptive governance. Global Environ. Change 30, 56-67. doi:http://dx.doi.org/10.1016/j. gloenvcha.2014.10.009.

Niki Frantzeskaki holds a PhD on 'Dynamics of Sustainability transitions' from Delft University of Technology and is an Associate Professor on Sustainability Transitions Governance at DRIFT, Faculty of Social Sciences at Erasmus University Rotterdam. She is working at DRIFT since 2010 where she researches contemporary sustainability transitions and their governance across Europe (UK, Greece, Italy, the
Netherlands) and in developing countries like Vanuatu and Ghana. She is coordinating research on environmental governance, transition management and urban living labs for urban sustainability transitions by leading and being involved in a portfolio of research projects including: URBES, ARTS, IMPRESSIONS, GUST RESILIENT EUROPE, and SUSTAIN.

Nadja Kabisch holds a PhD and a Diploma in Human Geography from the MartinLuther University Halle-Wittenberg, Germany, and is a senior researcher at the Humboldt-Universität zu Berlin in the Department of Landscape Ecology. She is also a researcher at the Helmholtz Centre of Environmental Research-UFZ, Department Ecosystem Services and part of the Ecosystem Services research lab within the German Centre of Integrative Biodiversity Research (iDiv) Leipzig-Halle-Jena. Nadja works in the EU-projects URBES and GREEN SURGE and is involved in the BfN project "Biodiversity and Climate Change" (BioClim). She has wide expertise in nature-based solutions, and ecosystem services of urban green spaces across European cities. 